\title{
O Encontro das Águas: \\ Breves Notas Introdutórias sobre a Pós-Modernidade
}

\author{
The Meeting of the Waters: \\ Brief Introductory Notes about Post-Modernity
}

Eduardo Portanova Barros ${ }^{1}$, Diego Airoso da Motta ${ }^{2}$

\section{Resumo}

O presente artigo visa a discutir, de maneira introdutória, as implicações da condição pós-moderna na teoria social e nas sociabilidades contemporâneas. Para tanto, inicialmente é traçada uma definição mais ampla do tema, a partir de seu cotejamento com as características da modernidade, com ênfase para sua crítica relativa às grandes narrativas e ao pensamento binário moderno e para aspectos teóricos que o uso do prefixo pós faz emergir. Além disso, procura-se resgatar as contribuições ao debate pós-moderno, com base nas ideias, entre outros, de Maffesoli, Huyssen, Vattimo, Bauman, Morin, Hall, Jameson, Derrida e Lyotard. O texto se dedica a refletir sobre alguns dos tantos desdobramentos da questão pós nas diversas discussões promovidas nas ciências humanas, como a dinâmica da identidade e a abordagem dos teóricos pós-colonialistas.

Palavras-chave: Pós-modernidade. Sociabilidade. Teoria social. Pós-estruturalismo. Pós-colonialismo.

\begin{abstract}
This article aims to discuss, in an introductory manner, the implications of the postmodern condition in the social theory and contemporary sociabilities. To do so, it is initially drawn a broader definition of the subject from its mutual comparison with the characteristics of modernity, with emphasis on its relative critique to the grand narratives, modern binary thinking and the theoretical aspects that the use of the prefix post brings out. In addition, we seek to recover contributions to the postmodern debate, based on the ideas, among others, of Maffesoli, Huyssen, Vattimo, Bauman, Hall, Jameson, Derrida and Lyotard. The text is devoted to reflect on some of the many developments about the post issue after several discussions promoted in the humanities, such as the identity dynamics and the post-colonialists theorists approach.
\end{abstract}

Key words: Post-modernity. Sociability. Social theory. Post-structuralism. Postcolonialism.

\footnotetext{
${ }^{1}$ Jornalista, mestre em Ciências da Comunicação (ECA/USP), doutor em Comunicação Social (PUCRS), pós-doutorando PNPD/CAPES/Unisinos no Programa de Pós-Graduação em Ciências Sociais da Unisinos. E-mail para contato: eduardoportanova@yahoo.com.br.

${ }^{2}$ Mestrando no Programa de Pós-Graduação em Ciências Sociais da Unisinos. E-mail para contato: diegoairoso@yahoo.com.br.
}

Esta obra foi licenciada com uma Licença Creative Commons - Atribuição 3.0 Não Adaptada. 


\section{Introdução}

A modernidade, com seu fundamento racional, sempre se conduziu sob uma ótica teleológica. Dentro dessa busca por finalidades, uma das mais contundentes talvez tenha sido a procura por verdades estáveis, o que supõe a constituição de certezas sobre a realidade sensível e pensável. Isso até pouco tempo. Agora, situações com que cotidianamente nos defrontamos ao ligar a televisão ou ao sairmos em passeio no centro da cidade, por exemplo, nos colocam em contato com uma realidade fluida, dispersa, efêmera e complexa. Neste cenário, torna-se possível sustentar, sem maiores esforços argumentativos, apenas uma certeza: vivemos outro momento na história da humanidade, no qual o (modernamente apocalíptico?) prognóstico de Marx, de que toda a solidez estaria se desmanchando no ar, salta aos olhos. É dessa certeza que se trata quando se discute a questão pós, da qual, quem sabe por melhor se encaixar em uma ideia de apreensão do zeitgeist (o espírito do tempo), o termo pós-modernidade seja o carro-chefe conceitual $^{3}$, trazendo consigo uma série de outros tantos pós, que nos remetem a vários "fins" originados a partir da modernidade (TORO, 1999) e que, de uma maneira ou outra, vão tentar dar conta do atual momento do desenvolvimento humano. Não que a modernidade e seus efeitos tenham "acabado", embora o prefixo pós induza naturalmente a esse raciocínio. Porém, argumentam os teóricos, aquela modernidade da fixidez, da teleologia, do progresso, do determinismo, que não tolera a ambiguidade já não existe mais. Em suma, a questão pós se manifesta no exato instante em que a modernidade se contradiz e entra em crise.

Inicialmente restrita ao âmbito da arquitetura, no final dos anos 1940 e início dos 1950, a discussão sobre o pós-moderno vai se referir à propensão de mesclar diferentes estilos, âmbito no qual se convencionou a utilização do termo "pósmodernismo". A questão, contudo, não precisou esperar muito para assumir um

\footnotetext{
${ }^{3}$ As precisões conceituais sobre a questão pós, especificamente no que se refere à diferenciação entre pós-modernismo e pós-modernidade, são controversas, mas, usualmente, relacionam pósmodernismo ao campo da arquitetura, das artes e de uma tal sensibilidade pós-moderna, enquanto a pós-modernidade se ligaria mais à ideia de um diagnóstico histórico e teórico social. Peters (2000, p.13-14), por exemplo, vai dizer que "o pós-modernismo tem, assim, dois significados gerais, relacionados aos dois sentidos de 'modernismo': ele pode ser utilizado, esteticamente, para se referir, especificamente, às transformações nas artes, ocorridas após o modernismo, ou em reação a ele; ou, em um sentido histórico e filosófico, para se referir a um período ou a um ethos - a 'pósmodernidade"'.
}

Cad. de Pesq. Interdisc. em Ci-s. Hum-s., Florianópolis, v.13, n.102, p.4-26 jan/jul 2012 
lugar privilegiado nos debates dentro de diversos outros ramos do conhecimento, como a história, a sociologia ${ }^{4}$, a literatura e as artes (PETERS, 2000).

No entanto, essa preocupação com a pós-modernidade só ganha significado porque, antes de ser considerado um tema relevante para as diferentes áreas do saber, ela se faz mais e mais presente na concretude da realidade humana. Ela se apresenta como uma nova sensibilidade ligada, por exemplo, aos movimentos culturais dos anos 1960, 1970 e 1980, na Europa. Huyssen (1992) fala da pósmodernidade como uma transformação cultural, uma mudança de sensibilidade, e não apenas uma tendência. É preciso atenção, porém, ao seguinte: todo estatuto da modernidade foi regido pela ideia do novo. Admitir o novo na pós-modernidade seria contrariar sua própria natureza pós-moderna, que privilegia, antes, a sensibilidade como uma questão vinculada ao termo, e não separada dele. Isolar é prerrogativa do novo. Por isso, tendência parece ser, mesmo, o termo mais adequado, no sentido de incorporar elementos. O prefixo "pós" dá margem a esse tipo de questionamento, a menos que nós aceitemos seu caráter ambíguo: tanto pode ser um "pós" que vem depois de algo, no caso o novo, quanto o de um "pós" que sinaliza para algo, no caso a tendência. É difícil conceituar. $E$ a dificuldade de conceituação já é um sinal de pós-modernidade.

Pois é sobre esse novo momento da condição humana que o presente artigo, a título introdutório, se propõe tratar, ainda que de forma confessamente limitada, dada a complexidade, "inacabamento" e contemporaneidade do tema. Para conduzir essa tarefa, concebemos o texto em seções: alguns aspectos conceituais da pósmodernidade e seus interstícios, sobreposições e refutações à modernidade; os subsídios trazidos por alguns pensadores pós-estruturalistas à questão "pós"; alguns dos vários temas que, além da temática da pós-modernidade em si, orbitam-na e, ao mesmo tempo, servem para diagnosticá-la. Por fim, tecemos algumas considerações, costurando algumas ideias tratadas num exercício de síntese, sem a pretensão de sermos dialéticos ou impondo nossa apreensão particular ao exposto.

\footnotetext{
${ }^{4} \mathrm{O}$ pensamento sociológico pós-moderno, por exemplo - o que precisamente nos toca -, que bebe na fonte das teorias já existentes, especialmente as linhas de Weber e Simmel, surge nos anos 70 e 80, nos EUA e Europa, principalmente na França, com Lyotard.
}

Cad. de Pesq. Interdisc. em Ci-s. Hum-s., Florianópolis, v.13, n.102, p.4-26 jan/jul 2012 


\section{Novas lentes para uma nova realidade}

Falar em pós-modernidade, efetivamente, é um desafio, inclusive para iniciados no tema. A própria natureza daquilo que a discussão da questão pós - que, no mínimo, amplifica o debate para as noções de pós-estruturalismo ${ }^{5}$ e póscolonialismo, por exemplo ${ }^{6}$ - propõe, torna-a uma ideia de difícil digestão para os que apreciam definições conceituais objetivas e categóricas, tão características do racionalismo moderno: "O seu caráter escorregadio desenha um espaço de conhecimento multifacetado, de difícil definição, de dinamismo e mutabilidade constantes" (GADEA, 2007, p. 11). Contudo, mostra-se um bom ponto de partida para falar do que se trata. Afinal, a pós-modernidade encaminha a discussão por meio de seu cotejamento com a modernidade, com a qual umbilicalmente se relaciona - como a própria expressão sugere ${ }^{7}$.

Poderíamos vincular a modernidade às características do racionalismo, do cientificismo, do empirismo e do historicismo. A pós-modernidade, por sua vez, apresentaria o inclusivismo, o afetual, a incerteza, o fluido, o líquido (Bauman) e o reconhecimento da ambiguidade - que a modernidade contém, mas não admite dentre seus traços marcantes. De fato, a modernidade tinha como projeto tentar eliminar a ambiguidade, mas não o consegue porque ela própria, na experiência concreta, vive na ambiguidade, como bem atestaram os frankfurtianos em sua denúncia sobre a neutralização da potência libertadora moderna por sua efetiva capacidade de instrumentalizar a razão para oprimir e fazer morrer. Assim, efetivamente, o que prevalece na modernidade é o indeterminismo, já que a síntese

\footnotetext{
${ }^{5}$ Embora, segundo alguns autores, tenha nascido nos Estados Unidos, como uma resposta ao estruturalismo, sobretudo de Lévi-Strauss, Althusser, Lacan e Barthes, "foi, sem dúvida, central para a emergência do pós-estruturalismo a redescoberta, por um grupo de pensadores franceses, da obra de Friedrich Nietzsche. Foram importantes também a interpretação que Martin Heidegger fez dessa obra, bem como as leituras estruturalistas tanto de Freud quanto de Marx" (PETERS, 2000, p.30).

${ }^{6}$ Gadea (2007) lembra ainda da pós-vanguarda, do pós-industrialismo, da pós-história, entre outras tentativas de, em diferentes instâncias de análise, descrever a contemporaneidade.

7 Cabe aqui um parêntese: uma das características da visão pós-moderna é sua aversão ao pensamento binário, que reduz e simplifica a análise de fenômenos que invariavelmente são complexos, especialmente dentro do campo de visão das ciências sociais. Porém, tratar de um objeto de conhecimento a partir da comparação de seus elementos, mesmo que sejam dois e que um deles seja a própria pós-modernidade, a nosso ver, por si só não elimina a validade analítica da tarefa. $O$ que inviabilizaria esta perspectiva de análise seria, sob nosso ponto de vista, o tratamento da questão a partir da consideração apenas de uma (embora sempre importante) relação de oposição entre os termos e, ainda, como agravante, a deliberada desatenção ao fato de que haveria muitas outras dinâmicas relacionais entre eles e tantos outros elementos, além dos dois, orbitando sua existência conceitual e o plano de seu entendimento. Não é o que se pretende fazer aqui, embora fugir a essa "tentação epistemológica" não seja fácil.
}

Cad. de Pesq. Interdisc. em Ci-s. Hum-s., Florianópolis, v.13, n.102, p.4-26 jan/jul 2012 
que a dialética moderna quer produzir não é alcançada. É por isso que a pósmodernidade tem lugar: é ela que reconhece a existência e o valor cognitivo da ambiguidade; é ela que abarca esse foco no efêmero, na experiência (que não se confunde com experimentação ${ }^{8}$ ), no que está sendo.

Alguns teóricos, como o sociólogo polonês Zygmunt Bauman, recorrem ao uso da metáfora para tentar uma aproximação com essa natureza ambígua da pósmodernidade. Bauman criou, assim, para designar a sociedade contemporânea, o termo "líquido". É uma forma de distinção daquilo que é sólido, isto é, representativo dos valores que pareciam, nos últimos dois séculos, perenes como a crença no futuro e no projeto político. A sociedade, para Bauman (2001), está em permanente mudança. Bauman observa nas características dos fluidos (a qualidade dos líquidos e dos gases) a mesma situação de uma sociedade que chamará de "líquida". Isso porque, explica o sociólogo polonês, "os líquidos, diferentemente dos sólidos, não mantêm sua forma com facilidade" (BAUMAN, 2001, p. 8). Outra analogia possível com a metáfora da "liquidez", segundo Bauman, é que "os fluidos não se atêm muito a qualquer forma e estão constantemente prontos (e propensos) a mudá-la" (2001, p. 8). O que acontece hoje, efetivamente, é, conforme Bauman, "um derretimento dos sólidos" (2001, p. 9). O "sólido" pode ser, por exemplo, a ordem econômica, hoje globalizada. O empenho de Bauman em salientar diferenças tem um caráter antes paradoxal do que dicotômico. Se no primeiro caso um polo pode ser adicionado ao outro para uma conjunção teórica que dará um novo sentido ao par de opostos, já no segundo caso não, pois o que é polarizado permanece nessa dimensão conflitante, sem uma aproximação dos contrários em direção a um novo significado. Bauman, portanto, é um dos teóricos que contribuem para a abordagem que nos leva a pensar no caráter pós-moderno da sociedade no século 21.

Para Gadea (2007), a pós-modernidade não deve ser vista como um conceito, mas sim como uma categoria que se refere a manifestações concretas das sociabilidades contemporâneas, contingentes e em interação com os fenômenos sobre os quais trata. Isso, de certa forma, demonstra a ligação que se estabelece entre a compreensão da pós-modernidade com as noções próprias ao pragmatismo e à corrente sociológica interacionista, evidenciando sua importância tanto como tema do debate filosófico (uma categoria analítica do pensamento) quanto do

\footnotetext{
${ }^{8} \mathrm{O}$ que sugere uma discussão sobre o pós-vanguardismo, tema sobre o qual nos absteremos neste texto.
} 
diagnóstico sociocultural (um componente da realidade social). Maffesoli irá rejeitar, categoricamente, a ideia de conceito, preferindo o termo noção. O conceito tem uma conotação de algo fechado, perpétuo, inquestionável, ao passo que a noção se debruça nas aproximações. Por outro lado, quando queremos definir o positivismo, por exemplo, temos de usar conceito mesmo, porque, sendo um termo paradigmático do espírito positivo, isto é, aquele puramente racional, seria estranho falarmos de uma noção de positivismo. Quando um termo, porém, oferece múltiplas leituras e é recente, aí sim noção é a melhor forma de defini-lo. Por exemplo, o tribalismo em Michel Maffesoli (2000).

A propósito, em termos de teoria social, o discurso pós-moderno se utiliza de enfoques teórico-analíticos que supostamente sempre gozaram de pouco espaço dentro dos horizontes epistemológicos das ciências sociais e da filosofia, como o pensamento de Simmel, de seus debatedores e sucessores, da fenomenologia, do interacionismo simbólico e da etnometodologia, além do pragmatismo e do pósestruturalismo, pois prestam atenção às ironias, à ambivalência, ao fragmento, ao situacional, ao contingente, diferentemente do que propunha o estruturalismo e o funcionalismo, que, de sua parte, nunca esconderam sua preocupação em tentar compreender a realidade a partir de um olhar totalizante e determinista (GADEA, 2007).

É possível afirmar que as origens da reflexão pós-moderna estejam na crítica radical de Nietzsche e Heidegger à herança do pensamento europeu, sobre o qual, entretanto, evitavam propor uma superação, simplesmente pelo fato de que, se assim agissem, reproduziriam a mesma lógica de desenvolvimento a que estavam atacando. Essa é, pelo menos, a ideia de Gianni Vattimo (1999). Para os filósofos alemães, a modernidade se caracterizava pela concepção de que a história do pensamento humano correspondia a uma iluminação progressiva, uma linha evolutiva baseada na ideia de constante superação, pela apropriação e reapropriação do fundamento, das origens do pensamento (VATTIMO, 1999). Em outras palavras, negavam a existência de bases apriorísticas de elaboração do pensamento e de busca da verdade, lançando as bases para sua discussão em termos de contingência, como evento ${ }^{9}$.

9 Ao discutir a questão da arte na época contemporânea, Vattimo (1999) vai falar que a reprodutibilidade técnica da arte - promovida na modernidade - levou-a a todos os lugares, tudo se estetizando, no que Heidegger chamou a morte (ou ocaso) da arte. Por consequência, estando em Cad. de Pesq. Interdisc. em Ci-s. Hum-s., Florianópolis, v.13, n.102, p.4-26 jan/jul 2012 
Uma das ideias de Nietzsche para questionar o "ocidentalismo" (que poderia ser traduzido por modernidade) diz respeito à noção de verdade. Para ele e para os pós-modernos (daí uma relação clara do filósofo alemão com a pós-modernidade) não existe uma verdade em si. Tudo é relativo, principalmente o "conceito" de verdade. "A verdade é agora simbolizada, ela se serve da aparência, ela pode e precisa por isso também usar as artes da aparência" (NIETZSCHE, 2005, p. 31). Isso pelo fato de que a aparência não carrega, ao contrário da ideia de conteúdo, um espírito soberbo, arrogante, escondido. Toda a filosofia de Nietzsche, aliás, servirá de base para os eixos investigativos de Maffesoli, a saber: o não-racional, o trágico e o sujeito (este não mais senhor de si, mas antes afeito ao outro). Não é à toa que o sociólogo da pós-modernidade irá intitular "No fundo das aparências", um de seus livros, o recurso linguístico conhecido por "oximoro", a fim de reunir na mesma expressão dois termos antagônicos (fundo x aparência; razão x sensível) para sugerir uma conotação não tão rígida, uniforme ou linear da socialidade (sic) pósmoderna.

\subsection{As grandes narrativas}

Talvez seja Jean-François Lyotard o pensador que mais amplamente deu vazão à discussão sobre a pós-modernidade. Com a obra "A condição pósmoderna", originalmente publicada em 1979, Lyotard "estava preocupado com os grandes relatos (ou as grandes narrativas), desenvolvidos a partir da llustração, marcando, assim, a modernidade" (PETERS, 2000, p. 17-18). Nesse contexto, as grandes narrativas, ou metanarrativas, seriam aquelas histórias que as culturas contam para legitimar suas crenças, suas práticas, sua visão de mundo, e assim legitimarem a si próprias como um todo coeso e unitário, que se autonarra (PETERS, 2000; GADEA; 2007). É justamente no fundamento dessa legitimação da cultura moderna que Lyotard vai plantar sua crítica, diagnosticando a existência de uma profunda crise e impugnando a ideia de que ainda seja possível formular uma visão de mundo a partir de "referentes universais de valor". Entre estes, estaria a busca pela verdade, a ser alcançada por meio da razão, ou uma manifestação

todos os lugares, não se sustentaria mais uma ideia apriorística de arte, mas sim sua definição no lugar mesmo onde se manifeste, de forma contingente. Da mesma forma, a verdade que a arte tematiza torna-se um evento e não uma estrutura fixa. 
específica dela - a razão moderna (ocidental, iluminista, cientificista, instrumental) -, que visaria unificar o espírito humano e serviria de base para definir quais disposições sociopolíticas estariam bem colocadas em termos de busca pelo progresso e pela emancipação; estes, por sua vez, pressuporiam uma temporalidade-evolutiva teleologicamente concebida, cuja linearidade daria conta de uma história humana única, universal.

Lyotard afirma que "o saber pós-moderno refina nossa sensibilidade para as diferenças e reforça nossa capacidade de suportar o incomensurável" (1989, p. 13). Esse filósofo francês tem o mérito de ter alavancado a discussão sobre a pósmodernidade. Admitir, como ele admitiu, a incomensurabilidade - isto é, aquilo que não podemos medir - confronta um tipo de pensamento, o pós-moderno, à pretensão de certeza da modernidade por meio dos saberes científico e técnico. Outra questão levantada por Lyotard é o fato de que "o saber pós-moderno não pensa por oposições" (1989, p. 39). A tentativa de legitimação de uma ideia por oposição à outra, fazendo com que uma delas tenha de ser eliminada por seu caráter pretensamente falso, não faria mais sentido na pós-modernidade. Não é que não se distinga. O problema é que a distinção passa a ser secundária em relação a fatores como, por exemplo, o da autoria ou o da arte culta. Lyotard questiona a validade dos enunciados narrativos. De acordo com ele, "o saber narrativo toma o científico como uma variedade entre as culturas narrativas, enquanto o saber científico interroga-se sobre a validade dos enunciados narrativos" (1989, p. 61). Disso resulta, segundo ele, "o imperialismo cultural comandado pela exigência da legitimação" (LYOTARD, 1989, p. 61).

Entre as grandes narrativas da modernidade, portanto, estariam os ideários do progresso, da emancipação, da razão, da história, do universal e do uno, da busca por uma verdade totalizante e, junto deles, as manifestações culturais, sociais e políticas que os materializariam, como o poder das estruturas (estáveis e sólidas), a legitimidade das instituições, principalmente o Estado, a ciência instrumentalizada para a ampliação do capital e da dominação política, a socialidade ancorada no valor do indivíduo (e sua liberdade) e a visão da realidade baseada no pensamento binário. $\mathrm{O}$ pós-moderno definitivamente refuta a crença nas metanarrativas, o que, porém, nos instiga a elaborar uma provocação de que mais adiante trataremos: a afirmação de que a realidade humana não mais pode ser explicada a partir de metanarrativas não constitui por si só uma metanarrativa? 


\subsection{0 encontro das águas ${ }^{10}$}

Embora as aparências terminológicas nos levem a pensar que a pósmodernidade seja um momento do pensamento humano que se instala linear e evolutivamente após a modernidade, na realidade ambas se relacionam contemporaneamente. Moderno e pós-moderno andam juntos, no mesmo contexto, ou seja, essa relação não se dá necessariamente em termos de oposição categórica. Nesse caso, o menos impreciso é falar que a pós-modernidade se coloca em uma posição que inclui e, ao mesmo tempo, supera a modernidade (GADEA, 2007). Com base em Roberto Follari, Gadea (2007, p. 32) vai dizer ainda que a pósmodernidade "é sim a finalização da modernidade, em que esta, através de seu próprio impulso, nega-se a si mesma".

O pós de pós-moderno indica, com efeito, uma despedida da modernidade, que, na medida em que quer fugir das suas lógicas de desenvolvimento, ou seja, sobretudo da ideia da "superação" crítica em direção a uma nova fundação, busca precisamente o que Nietzsche e Heidegger procuraram em sua peculiar relação "crítica" com o pensamento ocidental (VATTIMO, 1999, p. VII).

Lyotard (1984 apud PETERS, 2000, p. 19), por sua vez, vai dizer que o pósmodernismo, no que se refere ao campo das artes ${ }^{11}$, não é

"o modernismo no seu estado terminal, mas no seu estado nascente, e esse estado é constante. Eu disse e direi outra vez que o pós-modernismo significa não o fim do modernismo, mas uma outra relação com o modernismo",

definindo-se, segundo Peters (2000), como "um estilo, um ethos e não um período" que viria após o modernismo (p. 19, grifo do autor). De sua parte, Huyssen (1992), ao falar especificamente sobre as implicações do pós-modernismo no desenvolvimento das artes, destaca seu aspecto relacional, em que as contradições, as oposições, não servem a seu entendimento; os diferentes estilos convivem ou se antagonizam de forma eclética, plural. Modernidade e pós-modernidade não

\footnotetext{
${ }^{10}$ Uma das principais atrações de Manaus/AM é o fenômeno conhecido como "encontro das águas", em que o Rio Negro, cujo nome define a característica de suas águas, se encontra com o Rio Solimões, de água barrenta, sem que, no entanto, se misturem efetivamente e dividindo o mesmo leito por vários quilômetros. Ainda assim, compõem um mesmo conjunto hídrico, inseparável, interrelacionado. Pareceu-nos uma metáfora cabível à relação entre modernidade e pós-modernidade.

${ }_{11}$ Huyssen (1992) sugere diferenças entre pós-modernidade e pós-modernismo, este mais ligado ao campo das artes, aquela dizendo respeito à teoria social.
}

Cad. de Pesq. Interdisc. em Ci-s. Hum-s., Florianópolis, v.13, n.102, p.4-26 jan/jul 2012 
estariam, portanto, em relação de contradição e tampouco de progressão evolutiva $^{12}$, mas constituiriam sim formas diferentes de apreender a sensibilidade contemporânea.

Isso nos leva a pensar a pós-modernidade como uma "mais modernidade", mas somente na medida em que a modernidade se funda sobre a crítica ao que está posto, para chegar à constituição do "novo" - que de fato não se descola do "antigo" a que supostamente visa a substituir ${ }^{13}$. Contudo, é chegado o momento em que essa crítica se volta sobre a própria modernidade e passa a questionar aquilo que nela é "dado e admitido como válido e legítimo" (GADEA, 2007, p. 28).

Nessa lógica, a pós-modernidade, de certo modo, vem antes da modernidade na medida em que estabelece um momento crítico a esta, o que lhe permite se reler, superando essa crítica e se modificando. "Uma obra [de arte] só pode tornar-se moderna se primeiro for pós-moderna" (LYOTARD, 1999, p. 24). Ao mesmo tempo, o novo quadro que aí se forma retroalimenta uma nova crítica a ser efetivada pela pós-modernidade. Abre-se, ao que parece, espaço para uma relação causal recursiva e não necessariamente linear, como na modernidade, aproximando-se do diagnóstico que Morin (1990) encaminhou sob a noção de "pensamento complexo", para ele, característico de nosso tempo ${ }^{14}$.

\section{A contribuição do pós-estruturalismo}

Em sua matriz de criticidade, a pós-modernidade se apresenta como uma instância de contestação dos apriorismos, inclusive (e mais do que quaisquer outros) os que a modernidade instituiu. Para a pós-modernidade, não há coisa alguma dada de antemão, tudo é contingente e, por isso mesmo, complexo. Logo, subverte a dinâmica presente no modo moderno de conceber a realidade baseado em binarismos, que condensam o pensamento sob uma lógica unitária e invariável de exclusão/inclusão dos elementos em categorias que se opõem, como formula a

${ }^{12}$ O questionamento sobre a existência ou não de uma suposta linearidade evolutiva entre modernidade e pós-modernidade é um dos pontos de choque entre Lyotard e Habermas, já que este argumenta que não haveria como se falar em pós-modernidade quando, em sua maneira de ver, a modernidade não estaria concluída.

${ }^{13}$ Conforme Vattimo (1999, p. XII), "a novidade nada tem de 'revolucionário' e perturbador, ela é o que permite que as coisas prossigam do mesmo modo".

${ }^{14}$ As três causalidades apontadas por Morin (1990) no pensamento complexo seriam a linear (a causa condicionando o efeito), a retroativa (o efeito retroagindo sobre a causa) e a recursiva (causa e efeito se determinando recorrentemente).

Cad. de Pesq. Interdisc. em Ci-s. Hum-s., Florianópolis, v.13, n.102, p.4-26 jan/jul 2012 
dialética hegeliana e as formas de pensamento que bebem em sua fonte, especialmente a concepção marxista da luta de classes como motor da história, e também a psicanálise freudiana e o conflito entre pulsões internas (desejo) e os freios da cultura (repressão). Questiona-se fundamentalmente o reinado do n. "1", já que na dialética se contrapõe uma tese (um 1') à sua antítese (um 1") para se chegar a uma síntese (um 1), uma ideia única, totalizante. Talvez tenha sido no pensamento pós-estruturalista de Gilles Deleuze que a crítica à dialética tenha ganhado contornos mais claros. Propondo a afirmação da diferença contra a "negação da negação" característica da dialética, Deleuze busca substituir Hegel por Nietzsche (PETERS, 2000).

\begin{abstract}
Devemos compreender o pós-estruturalismo, no seu desenvolvimento no contexto histórico francês, tanto como uma reação quanto como uma fuga relativamente ao pensamento hegeliano. Essa reação ou fuga, para sintetizar a questão em termos deleuzianos, envolve, essencialmente, a celebração do "jogo da diferença" contra o "trabalho da dialética" (PETERS, 2000, p. 33).
\end{abstract}

Essa perspectiva abre a análise para uma perspectiva plural, complexa, dos fenômenos humanos, para além de sua elaboração como o saldo de opostos que se anulam. A realidade é um sistema aberto, onde as contradições internas e externas interferem nos fenômenos como uma característica intrínseca ${ }^{15}$.

Nessa mesma direção, a partir do pensamento de Nietzsche, Heidegger (sempre eles) e Saussure, Jacques Derrida, outro pós-estruturalista, apresenta a ideia de desconstrução, que muito vai participar da formatação filosófica e, ao mesmo tempo, metodológica do que se poderia chamar uma sensibilidade pósmoderna. A desconstrução vai refutar as oposições binárias que, no pensamento de Derrida, "sustentam sempre uma hierarquia ou uma economia do valor que opera pela subordinação de um dos termos da oposição binária ao outro, utilizando a desconstrução para denunciar, deslindar e reverter essas hierarquias” (PETERS, 2000, p. 32). O próprio Derrida afirma: "Desconstrução é também a reação contra essa hegemonia" (1998, p. 96). O filósofo francês, nascido na Argélia, explica que cresceu em meio ao que denomina "teoria marxista envelhecida" (1998) e que, para

15 Para Morin (1990), a complexidade do real exige a substituição do paradigma da disjunção/redução/unidimensionalização pelo da distinção/conjunção/multidimensionalização. Conforme o autor, essa complexidade vai abarcar em um mesmo plano de análise a ordem, a desordem e a organização, articulados complementarmente, constituindo a dinâmica da realidade.

Cad. de Pesq. Interdisc. em Ci-s. Hum-s., Florianópolis, v.13, n.102, p.4-26 jan/jul 2012 
combatê-la, resolveu reagir. Percebe-se nele, portanto, uma mentalidade voltada para o confronto intelectual de natureza política, o que não caracteriza uma postura pós-moderna. Se Derrida colaborou para a introdução do pensamento pós-moderno no meio acadêmico, isso não significa dizer, por outro lado, que ele seja um representante dessa pós-modernidade. Nosso ponto, neste artigo, não é o de classificar autores como sendo desta ou daquela corrente, e sim apresentar teorias e não de forma exaustiva - que contribuíram para o debate em torno da pósmodernidade. E Derrida, aí sim, contribui nesse sentido, pois não há dúvida que, mesmo voltado para essa politização do debate acadêmico, que procura antes o convencimento argumentativo do que afinidades eletivas, Derrida desestabiliza o pensamento hegemônico com sua proposta desconstrutivista.

Neste momento, convém relembrar uma pergunta anteriormente deixada em suspensão e carente de discussão: Mas não seria a questão pós outra metanarrativa, ao explicar o todo pela ausência de metanarrativas? A discussão da pós-modernidade não estabeleceria um novo metadiscurso, uma nova referência hegemônica? Toro (1999) não elimina essa possibilidade, entretanto argumenta por sua improbabilidade, já que os elementos que dão corpo ao pensamento pósmoderno não substituem os velhos por novos referentes universais de valor. A forma como se constitui a pós-modernidade e seu instrumental crítico submetem-na à eterna volta a si própria, em uma autodesconstrução.

\begin{abstract}
Además la cultura postmoderna y el pensamiento postmoderno conllevaban el momento del nomadismo, del rizoma, de la diseminación, de la deconstrucción. Estas son operaciones teórico-intelectuales inherentes a su naturaleza, y por esto, existe desde adentro del sistema una resistencia a la implantación de formas postmodernas como un credo, como un metadiscurso universalizante y legitimista; naturalmente que existe un resto de riesgo a que la deconstrucción misma se establezca como canon permanente (TORO, 1999, p. 43)
\end{abstract}

Portanto, a desconstrução vai desmontar os elementos do discurso moderno, um por um, buscando seus pontos de ancoragem metanarrativos, apriorísticos e questionando sua validade, inclusive em relação àqueles que venham a se fazer sentir dentro da própria pós-modernidade. Percebe-se, enfim, a forte ligação do pensamento pós-moderno com o pós-estruturalismo, com o qual muitas vezes é confundido (PETERS, 2000). 


\section{4 fato do centro e outros pós}

A abordagem pós-moderna dos binarismos e do primado do n. ${ }^{\circ} 1$ nos leva a pensar sobre outro ponto chave para compreender a contemporaneidade: 0 enfraquecimento da valorização dada à ideia de centro. Esse debate, também de forte conotação pós-estruturalista, vai trazer à discussão pós-moderna a dimensão do pluralismo na compreensão da realidade social, traduzida, entre outros temas, no tratamento da questão identitária e nas noções de pós-história e pós-colonialismo.

\subsection{Identidade e identificações}

Examinar a temática da identidade é um momento crucial para a compreensão do que Lyotard chamou condição pós-moderna. Um dos autores mais destacados por sua abordagem à questão é Michel Maffesoli. Na obra "O tempo das tribos", Maffesoli (2000) vai diagnosticar a saturação da lógica relacional moderna, alicerçada no desencantamento do mundo e na valorização dos indivíduos e das associações contratuais e racionais entre eles. Esse quadro dá vazão a relações assentadas no afeto, na sensibilidade e na reciprocidade solidária. Substitui-se uma ordem política, que se liga à ideia de indivíduo e as funções que desempenha no todo - ou "o social" -, pela ordem da fusão, baseada no pertencimento à massa e a tribos que se gestam em seu interior, no que Maffesoli chama de socialidade.

Maffesoli vai colocar que sob a perspectiva da socialidade, mesmo que determinadas relações se estabeleçam por motivações econômicas, o que importa é o comum partilhado no instante mesmo em que a confluência entre os que se relacionam se concretiza. Logo, as relações, mesmo as aparentemente mais duras e frias, podem se estetizar, ludicizar.

[...] se é inegável que existe uma sociedade "política", e uma sociedade "econômica", existe também uma realidade que dispensa qualificativos, e que é a coexistência social como tal que proponho chamar socialidade, e que poderia ser a "forma lúdica da socialização" (MAFFESOLI, 1999, p. 114-114).

$\mathrm{Na}$ perspectiva moderna do indivíduo, se destaca o "eu", enquanto o comunitarismo pós-moderno enfatiza o "nós" e cria uma fusão que o autor define como desindividualizante, baseada na sintonia, na relação face a face, no táctil, no 
afeto, no "sensível que é o substrato do reconhecimento e da experiência do outro" (MAFFESOLI, 2000, p. 103), ainda que esta venha a ser de natureza conflitual. A modernidade prioriza o espaço público enquanto a pós-modernidade concebe suas energias a partir do espaço privado. Aquela produz um esvaziamento da esfera íntima que o caráter afetual desta remediaria, a partir do restabelecimento da dimensão comunitária.

Maffesoli se utiliza de recursos teóricos do pensamento de Georg Simmel, do interacionismo, da fenomenologia e, por que não dizer, do pensamento de Durkheim (basta lembrarmos a noção de solidariedade mecânica, embora esta remeta a um tribalismo clássico, em que vigora certa estabilidade) para elaborar suas ideias em torno da formação dessa nova sociabilidade a que chamou neo-tribalismo. Este valoriza o presente coletivamente vivido e não corresponde a nenhum projeto político teleologicamente direcionado, cambiando a lógica da identidade - base para uma ordem econômico-política e social macrodimensional e apriorística - pela das identificações, que agrega o estético como um momento político e que se funda na fluidez, na dispersão, no "estar junto à toa", na concretude das microrrelações e numa socialidade eletiva, o que de certa forma nos envia aos círculos sociais de Simmel.

\begin{abstract}
Característica do social: o indivíduo podia ter uma função na sociedade, e funcionar no âmbito de um partido, de uma associação de um grupo estável. Característica da socialidade: a pessoa (personna) representa papéis, tanto dentro de sua atividade profissional quanto no seio das diversas tribos de que participa. Mudando o seu figurino, ela vai, de acordo com seus gostos (sexuais, culturais, religiosos, amicais) assumir o seu lugar, a cada dia, nas diversas peças do theatrum mundi (MAFFESOLI, 2000, p. 108, grifos do autor).
\end{abstract}

$\mathrm{Na}$ verdade, o social e a socialidade, ou o eu e a massa/tribo, existem simultaneamente não havendo necessariamente uma substituição, isto é, macro e micro se relacionam e por conta disso dentro do mercado da massa há grande oferta de tribos, às quais podemos escolher. Se antes as identidades eram determinadas, inevitáveis, agora são eletivas, inclusive aquelas inscritas no corpo, com todas as consequências individuais e sociais que isso possa significar ${ }^{16}$.

${ }^{16}$ Exemplo emblemático disso é o caso de Michael Jackson, que, para além de suas grandes qualidades artísticas, notabilizou-se por fazer uso de diversas medidas cirúrgicas e cosméticas para se fazer (ou aparentar) ser branco. Tornou-se, por isso, "[...] um dos personagens culturais mais vilipendiados da história recente por sua decisão de não ficar 'em seu lugar', com isso irritando tanto Cad. de Pesq. Interdisc. em Ci-s. Hum-s., Florianópolis, v.13, n.102, p.4-26 jan/jul 2012 
$\mathrm{Na}$ sociabilidade contemporânea, o contingente passa a ser o elemento preponderante da constituição identitária, na medida em que esta se forma (e se reforma) na concretude das relações, no tempo e no espaço.

[...] conceitos tradicionais estão sendo revistos não porque alguém decidiu fazê-lo num gabinete, mas porque as pessoas o estão revendo nas ruas e em suas casas. Entre eles, os conceitos de identidade e identidade cultural, que cedem espaço para a ideia de identificação, ou processo de constante mudança de alguns ou da maioria dos traços descritores de um indivíduo ou grupo e que não desaparecem por completo como tais, é fato, mas que se fundem com outros, novos e acaso inesperados, num vasto processo aberto (COELHO, 2008, p. 53).

$\mathrm{Na}$ verdade, o que se apresenta, conforme Coelho (2008), não é necessariamente a exigência de que não deva mais haver identidades, mas sim a atenção para o fato de que estas não necessariamente têm de ser fixas, podendo assumir uma dimensão múltipla, polifônica, usando a terminologia de Edward Said, repercutida por este autor. Toro (1999), por sua vez, coloca que os processos de desterritorialização inerentes à globalização não significam que as identidades tenham perdido sua ancoragem, sobretudo cultural, mas sim que agora transitam em outros espaços. Tem-se aí o cenário para a emergência e fortalecimento de culturas flutuantes, pontos de vista flutuantes e identidades flutuantes.

Um dos aspectos sobre os quais Jameson se debruça para falar de uma nova ordem mundial é o da "mudança da dinâmica da patologia cultural" (1996, p. 42). Ou seja, afirma Jameson, "a alienação do sujeito é deslocada pela sua fragmentação" (1996, p. 42). Enfim, o sujeito está morto? Jameson presume que o pós-modernismo aponta para o fim desse dilema ao considerar supérfluo, por exemplo, a ideia de um estilo único e pessoal (1996, p. 43). A conotação de pós-modernismo de Jameson é de ordem político-cultural. Mais adiante, Jameson deixa claro que a sua visão de pós-modernismo é histórica. "É preciso insistir na diferença radical entre uma visão do pós-modernismo como um estilo e uma visão dele como a dominante cultural da lógica do capitalismo tardio" (JAMESON, 1996, p. 72). Stuart Hall, por sua vez, acentua na pós-modernidade as várias facetas da identidade, agora não mais centrada no sujeito monovalente. Diz ele que "somos confrontados por uma

os brancos que se viram invadidos em sua praia exclusiva pelo Outro quanto os negros que não aceitaram a 'traição' à 'classe' ou que se sentiram diminuídos pela ousadia que não puderam imitar. Tanto mais quanto o homem é cada vez mais um ser de cultura, não da natura - portanto, um ser que se define e se refaz, não um dado imutável" (COELHO, 2008, p. 64). 
multiplicidade desconcertante e cambiante de identidades possíveis, com cada uma das quais poderíamos nos identificar - ao menos temporariamente" (HALL, 1999, p. 13). O sentimento na pós-modernidade, como vimos com Jameson e Hall, entre outros autores, é o de descentramento do sujeito. Assume-se, agora, toda a carga complexa (incluindo nela contradições) dos atores nesse tecido conjuntivo com que uma sociedade enxerga a si mesma.

\subsection{A pós-história}

A relativização das fronteiras culturais e políticas caminha pari passu com a flexibilização da linearidade cronológica e a descentralização da produção das narrativas históricas a partir das quais, até então, a elaboração temporal dos feitos e fatos da humanidade esteve exclusivamente orientada. Supondo a possibilidade de a pós-modernidade cair na armadilha de reproduzir a lógica historicista moderna ao propor a superação dessa mesma lógica, Vattimo (1999) argumenta que o pósmoderno representaria a "dissolução da categoria do novo, como experiência de 'fim da história', mais do que como apresentação de uma etapa diferente, mais evoluída ou mais retrógrada, não importa, da própria história" (p. IX). O fim da história, nessas condições, se caracterizaria pelo fato de que ela, como um processo unitário, se dissolveria, "instaurando-se, na existência concreta, condições efetivas [...] que lhe conferem uma imobilidade realmente não-histórica" (p. X-XI). Com base em Arnold Gehlen, Vattimo (1999) revela que essa imobilidade se traduz em uma rotinização do progresso ${ }^{17}$, ou seja, o novo não produz mais o efeito de avanço a partir de um estado anterior e, logo, o progresso se esvazia. Faz entrar em cena, então, a ideia de "pós-história".

De certa forma, assim como a pós-modernidade supostamente não elimina a modernidade (pois não vem evolutivamente depois desta), a pós-história não suprime a história, mas sim uma determinada forma unitária dela: rompe sua unidade e a dissolve em histórias, em diversos planos e maneiras de reconstruir o passado na consciência e no imaginário coletivo. O ponto crucial - e mesmo paradoxal - dessa situação é que na contemporaneidade os avanços da tecnologia da informação e da comunicação, tão emblemáticos do fenômeno que viemos a

\footnotetext{
17 “[...] enquanto novos resultados sempre se tornarão alcançáveis, a capacidade de disposição e de planejamento os tornará cada vez menos 'novos"' (VATTIMO, 1999, p. XII).
}

Cad. de Pesq. Interdisc. em Ci-s. Hum-s., Florianópolis, v.13, n.102, p.4-26 jan/jul 2012 
conhecer por globalização, proporcionaram as condições para que, como nunca até então, a humanidade pudesse efetivar uma história universal, única. Contudo, justamente neste momento, e por conta disso mesmo, a elaboração dessa história una não é possível, já que "o mundo da mídia disseminada por todo o planeta também é o mundo em que se multiplicaram os 'centros' de história"18 (VATTIMO, 1999, p. XV-XVI). De acordo com Gadea (2007), uma visão cronológica e linear do tempo, ordenada a partir de um centro, é substituída por uma leitura que a transgride, que opera multidirecionalmente e que se recusa a buscar um horizonte predeterminado. Assim, subverte-se a realidade apontada por Benjamin e trazida por Vattimo de que a história só compunha um curso unitário, pois que contada pelos vencedores. Embora a mídia comercial, em termos mundiais e regionais, seja concentradora de poder, material e simbolicamente, as novas ferramentas comunicacionais abrem a possibilidade de um efetivo descentramento das narrativas históricas, o que, para Toro (1999), é um dos pontos-chave da globalização, promovendo visões de mundo plurais e em interação.

\subsection{A pós-colonialidade}

Elaborando uma forma de problematizar a realidade social baseada em princípios semelhantes, os pensadores conhecidos como pós-colonialistas têm constituído um importante corpo de reflexões sobre a contemporaneidade. Com a desestruturação formal do sistema colonial europeu, a intelligentsia das antigas colônias, dentro e fora delas, passou a produzir reflexões num primeiro momento voltadas à crítica literária (mas logo expandidas à teoria social) sobre os efeitos da nova "ordem" sociopolítica a que agora estavam lançados. Com base na teoria desconstrucionista de Derrida dentre outras influências, esses pensadores vão tentar polemizar e desfazer o discurso formador do sujeito subalterno, inicialmente estabelecido na relação dicotômica com a dominação metropolitana europeia, mas amplificado a outros campos discursivos, como a questão de gênero, racial e étnica. Como consequência, vão produzir uma releitura da episteme das ciências humanas

\footnotetext{
18 "[...] viver na história [...] é uma experiência que se tornou possível, sim, apenas para o homem moderno, porque somente com a modernidade (a idade de Gutenberg, segundo a exata descrição de McLuhan) criaram-se as condições para construir e transmitir uma imagem global das vicissitudes humanas; mas, em condições de maior sofisticação dos próprios instrumentos de coleta e transmissão da informação (a idade da televisão, ainda segundo McLuhan), tal experiência, de novo, se torna problemática e, afinal de contas, impossível" (VATTIMO, 1999, p. XVI).
} 
globalmente hegemonizada pelo processo de expansão colonialista e fatalmente ligada aos interesses políticos e econômicos do Ocidente.

As reflexões pós-coloniais se originam nos anos 1970, tendo como expoentes pensadores como Edward Said, Gayatri Spivak, Homi Bhabha e Bill Ashcroft (TORO, 1999), que, com diversas trajetórias pessoais e intelectuais, muitas vezes elaboradas dentro da metrópole ${ }^{19}$, provocam

una explosión en la historiografía y en la teoría de la cultura de donde luego [...] comienzan a aparecer publicaciones en África y Latinoamérica, especialmente a cargo de críticos literarios y antropólogos y también historiadores (TORO, 1999, p. 62).

Ainda de acordo com Toro, discutindo reflexões de Patricia Seed,

\begin{abstract}
El discurso colonial lo entiende Seed como una crítica que parte de la lengua de los conquistadores descubriéndola como hegemónica y homogeneizante, desarrollando así un contradiscurso anticolonial y nacional para liberarse del discurso de los colonizadores y mostrar cómo ese discurso debe ser leído.

[...] Said, Bhabha y Spivak que hacen una crítica tanto al discurso occidental de la periferia como al nacionalista de la era postcolonial; hablan del centro y con la lengua del centro, con la educación científica del centro sobre la periferia de donde provienen, deconstruyendo el discurso del centro y recodificándolo en un nuevo contexto. Estos autores, basados en el postestructuralismo, fundan un discurso 'postcolonial' que se diferencia del discurso colonial a través de su centro de atención o sus realidades históricas, pero aun más, es la hibridez del discurso postcolonial como principio y estrategia, esa transversalidad y 'altaridad' que lo marca, la descentración textual y su rizomática pluralidad (TORO, 1999, p. 62).
\end{abstract}

Dessa forma, o pós-colonialismo tenta driblar a lógica a que visa criticar, evitando contestar o discurso do centro por sua mera imagem especular, ou seja, pela simples inversão da relação centro-periferia que, de fato, acaba por operar nas mesmas bases do ponto de vista etnocêntrico (que neste caso apenas deixaria de ser eurocêntrico). Com isso, o pós-colonialismo, como nas ponderações de Spivak (2010), vai procurar implodir as bases sobre as quais o sujeito etnocêntrico colonizador se forma, no momento em que este denomina e aprisiona o Outro, dito

\footnotetext{
${ }^{19}$ Said, por exemplo, nasce em Jerusalém, na época sob domínio britânico, no seio de uma família de origem árabe, mas convertida ao cristianismo; cresce no Cairo, estudando em escolas de orientação anglicana e posteriormente migra para os EUA, onde complementa seus estudos e se torna professor universitário. Spivak, com uma biografia semelhante à de Bhabha, nasce em Calcutá, Índia, então colônia inglesa, onde realiza boa parte de sua formação intelectual e se muda para os EUA, tornando-se $\mathrm{PhD}$ e professora da Universidade de lowa. Atualmente leciona na Universidade de Columbia e é membro-visitante do Centre for Studies in Social Sciences de Calcutá.
} 
por ele como subalterno, constituindo o que ela chama de "violência epistêmica". Spivak, no clássico ensaio "Pode o subalterno falar?", vai justamente questionar esse estabelecimento do sujeito subalterno em sua demarcação como o Outro do sujeito imperialista, como sua sombra.

No que concerne, portanto, à ocorrência de um desvirtuamento do centro, se, ao tratarmos da pós-modernidade, falamos sobre uma desfronteirização horizontal do pensamento, quando manejamos a ideia de pós-colonialidade falamos em uma desfronteirização vertical da abordagem da realidade. Trata-se de um questionamento aos apriorismos políticos e sociais que estabeleciam as relações de poder entre centro e periferia e que, por extensão, condicionavam (e ainda condicionam, embora de forma sensivelmente mais complexa) diversas formas de manifestações socioculturais nos planos micro e macrológicos, desde as fricções entre comunidades desfavorecidas e bairros "nobres" das grandes e médias cidades até as relações econômicas internacionais entre países dos eixos norte/sul/leste/oeste.

Aqui e sempre, a discussão sobre a questão pós se dirige para a apreensão de uma realidade que abarca o múltiplo, o plural, o descentrado, o fluido.

\section{Considerações finais}

Há pelo menos meio século o cenário pós-moderno vem sendo sentido na realidade social e discutido nas mais diversas áreas do conhecimento, principalmente as que se dedicam à apreensão da sociabilidade, do pensamento e da expressividade humana. No limite, se considerarmos ao pé da letra a elaboração de Lyotard (1989, p. 79), a da perda de credibilidade das duas narrativas de legitimação da ciência (especuladora e emancipadora), a pós-modernidade sempre esteve aí, no outro lado do espelho da modernidade. Se desde ontem ou de hoje, talvez pouco importe; o fato é que falar em pós-moderno é tratar de uma realidade irreversível, mas ainda longe de poder ser totalmente definível. Os fenômenos, quando vividos contemporaneamente à análise que deles se faz, dão margem a uma certa nebulosidade sobre sua precisa causalidade, seus limites e seus efeitos possíveis. Ainda assim, com base não tanto em elucubrações originalmente produzidas nos gabinetes e encontros sobre Humanidades, mas sim na análise crítica da realidade concreta, efetivamente produzida nas trocas sociais do cotidiano, 
é possível listar, como fechamento dessas linhas introdutórias ao tema, algumas características pós-modernas que se traduzem em um reposicionamento de certas linhas da modernidade, principalmente, no que nos toca, em termos de pensamento sociológico.

Nesse sentido, a perda de sustentação dos metarrelatos que embasavam a modernidade poderia ser dito como um fator axial à constituição da condição pósmoderna. Junto com ele, o questionamento das estruturas - de poder e de pensamento - consolidou uma maneira de conceber a realidade que deslocou a antiga ênfase no macro pela relevância do micro, das relações sociais como elas efetivamente se dão na cotidianidade. Por conta disso, perdem terreno as relações binárias e apriorísticas na quais se fundavam as generalizantes macroexplicações do social, que tudo tendiam a reduzir a dois números uns que se opunham (uma visão totalizante do mundo contraposta a outra). Aqui se define a crítica radical feita à dialética hegeliana, bombardeada por uma concepção alicerçada na leitura de Nietzsche e Heidegger. Nestes autores, a ciência é secundária. Para Nietzsche, a salvação do homem se encontra na arte (2005). Para Heidegger, a dimensão crítica não pode repetir o modelo crítico ocidental. Destacaríamos, para exemplificar, o artigo de Heidegger "A questão da técnica" (2008). Segundo Heidegger, técnica não é o mesmo que a sua essência. E a essência dela - ao invés de buscarmos uma resposta unidimensional ou monovalente - apresenta uma característica ambígua. Não sendo um meio próprio, e sim uma forma de "des-encobrimento" para dela melhor se usufruir e, portanto, controlar, Heidegger irá afirmar, finalmente, que é na composição que repousa a essência da técnica (2008). E essa composição, continua ele, não tem nada de técnico. Vattimo (1999) afirma que Nietzsche e Heidegger, por causa dessa postura crítica em relação ao Ocidente, mas cientes de que superá-lo seria cair na armadilha da própria essência daquilo que criticam, podem ser considerados os dois filósofos da pós-modernidade.

Além disso, essa visão pragmática da realidade condiciona uma nova forma de abordar a temporalidade. Onde antes tínhamos uma ênfase temporal no futuro, no progresso, na teleologia, agora o tempo ao qual se dirigem os ânimos humanos é o presente, onde tudo efetivamente acontece e onde a contingência é a (des)ordem. Logo, a questão das identidades, fixas, estáveis, excludentes do Outro (mais uma vez o binarismo...) e deterministicamente elaboradas (...mais uma vez o apriorismo) também se modifica, dando espaço à preponderância da lógica das identificações, 
mais fluidas, arbitrárias e abertas, no tempo e no espaço, muito bem ilustradas pela noção de neo-tribos de Maffesoli ${ }^{20}$. Isso nos induz a pensar em outra questão fundamental ao que podemos chamar uma sensibilidade pós-moderna: a debilidade do centro, em favor do pensamento plural, múltiplo. Essa característica é fundamental para a reflexão política que se procure fazer sobre a contemporaneidade, essencialmente quando nos deparamos com um cenário geopolítico em que a relação metrópole-colônia cedeu seu lugar a uma "ordem" globalizada e baseada em um novo jogo de forças, mais amplo, disforme e multidirecional. Da mesma forma, a centralidade do Estado agora é flexibilizada não só pelo capital (que dele quer apenas aquilo que corresponde a seus interesses de autorreprodução), mas também pela atuação da sociedade civil, múltipla e conectada às diversas demandas sociais, de ontem (a questão das classes) e de hoje (os novos movimentos sociais). Não se pode deixar de considerar ainda a importância da valorização dada ao cultural em detrimento da centralidade do econômico na análise social, quer dizer, as ciências sociais passam a se dedicar tanto mais à dimensão da sensibilidade nos fenômenos sociais do que a racionalidade de um tal contratualismo social.

Por tudo isso, evidencia-se a complexidade do momento em que vivemos, o que por si já o caracteriza como um instante diferente na condução da humanidade, até bem pouco tempo (e ainda um tanto) preocupada em reduzir sua autocompreensão, sobretudo em sua vertente ocidental, a fundamentos e explicações simplificadas e totalizantes. Assim, sem querer ser demasiado esquemático, teríamos na pós-modernidade expressões como: pluralidade, ambivalência, imperfeição, tremor, sedução, impermanência, holismo, gasto (e também gosto), onírico, lúdico, ambiguidade e sombra. $\mathrm{Na}$ modernidade, prevalecem a assepsia, o indivíduo, o poder, a ordem e o progresso, o moralismo, a verdade, a autonomia, o ascetismo, a utilidade e o racionalismo. Esta sensibilidade alternativa à da modernidade é que pode fazer com que nos reconciliemos com o cotidiano.

\footnotetext{
${ }^{20}$ García-Canclini (2009) faz uma ressalva a uma suposta visão "romântica" da pós-modernidade, no que se refere a sua característica de relativizar a fixidez identitária, argumentando que estudos sobre o tema não costumam considerar os dramas individuais que um tal desenraizamento identitário pode produzir, principalmente quando os sujeitos envolvidos se colocam em condições muito intensas de valorização de origens étnicas, por exemplo.
} 


\section{REFERÊNCIAS}

BAUMAN, Zygmunt. Modernidade líquida. Rio de Janeiro: Jorge Zahar Ed., 2001.

COELHO, Teixeira. A cultura e seu contrário. São Paulo: lluminuras; Itaú Cultural, 2008.

DERRIDA, Jacques. Jacques Derrida e as visões de Marx. In: Visões de uma certa

Europa. Org: Juremir Machado da Silva. Porto Alegre: Edipucrs, 1998, p. 95-101.

GADEA, Carlos A. Teorias e pós-modernidade. In: Paisagens da pós-

modernidade: cultura, política e sociabilidade na América Latina. Itajaí: Univali, 2007. p. 23-100.

GARCÍA-CANCLINI, Nestor. Norte e Sul nos estudos culturais; Quem fala e em qual lugar: sujeitos simulados e pós-construtivismo. In: Diferentes, desiguais e desconectados. Rio de Janeiro: UFRJ, 2009. p. 149-160; 183-208.

HALL, Stuart. A identidade cultural na pós-modernidade. Rio de Janeiro: DP\&A, 1999.

HEIDEGGER, Martin. Ensaios e conferências. Petrópolis: Vozes, 2008.

HUYSSEN, Andreas. Cartografías del postmodernismo. In: PICÓ, Josep (comp.). Modernidad y postmodernidad. Madri: Alianza, 1992. p. 189-241.

JAMESON, Fredric. Pós-modernismo: a lógica cultural do capitalismo tardio. São Paulo: Ática, 1996.

LYOTARD, Jean-François. A condição pós-moderna. Lisboa: Gradiva. $2^{\mathrm{a}}$ ed., 1989.

LYOTARD, Jean-François. 0 pós-moderno explicado às crianças. 3. ed. Lisboa: Dom Quixote, 1999. 
MAFFESOLI, Michel. O tribalismo. In: O tempo das tribos: o declínio do individualismo nas sociedades de massa. Rio de Janeiro: Forense Universitária, 2000. p. 101-142.

MORIN, Edgar. Introdução ao pensamento complexo. Lisboa: Instituto Piaget, 1990.

NIETZSCHE, Friedrich. A visão dionisíaca do mundo. São Paulo: Martins Fontes, 2005.

PETERS, Michael. Pós-estruturalismo e filosofia da diferença. Belo Horizonte: Autêntica, 2000.

SPIVAK, Gayatri Chakravorty. Pode o subalterno falar? Belo Horizonte: UFMG, 2010.

TORO, Alfonso de. La postcolonialidad en Latinoamérica en la era de la globalización. ¿Cambio de paradigma en el pensamiento teórico-cultural latinoamericano?, In: TORO, Alfonso de; TORO, Fernando de Toro (Ed.): El debate de la postcolonialidad en Latinoamérica. Una postmodernidad periférica 0 cambio de paradigma en el pensamiento latinoamericano. Frankfurt am Main: Klaus Dieter Vervuert, 1999. p. 31-77. (TKKL/TCCL, vol. 18).

VATTIMO, Gianni. O fim da modernidade: niilismo e hermenêutica na cultura pósmoderna. São Paulo: Martins Fontes, 1999.

Artigo:

Recebido em: 20/09/2011

Aceito em: 20/06/2012 